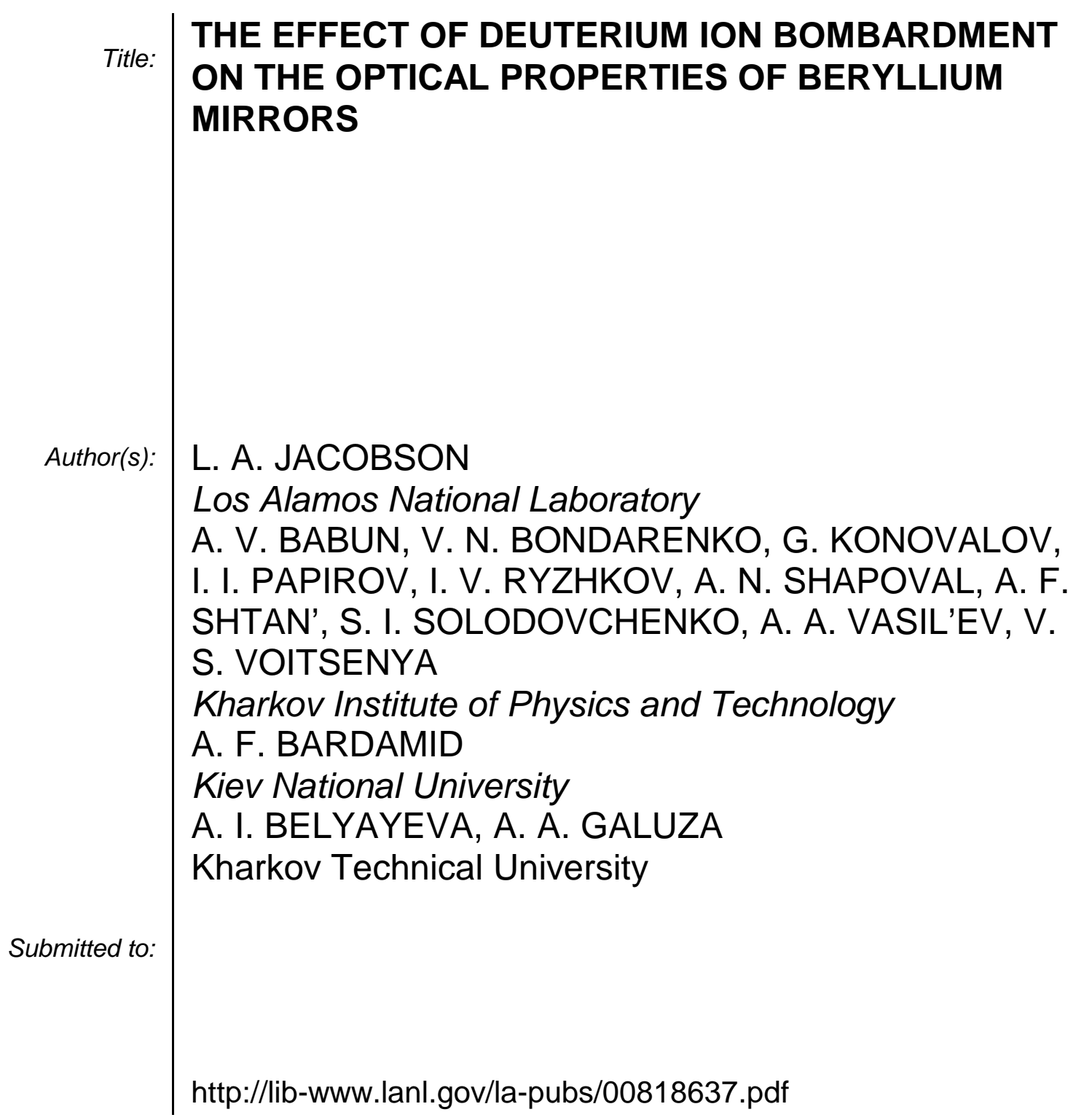




\title{
THE EFFECT OF DEUTERIUM ION BOMBARDMENT ON THE OPTICAL PROPERTIES OF BERYLLIUM MIRRORS
}

\author{
L. A. JACOBSON \\ Los Alamos National Laboratory \\ Los Alamos, NM 87545, USA
}

A. V. BABUN, V. N. BONDARENKO, G. KONOVALOV, I. I. PAPIROV, I. V. RYZHKOV, A. N. SHAPOVAL, A. F. SHTAN', S. I. SOLODOVCHENKO, A. A. VASIL'EV, V. S. VOITSENYA

Kharkov Institute of Physics and Technology

61108 Kharkov, Ukraine

\author{
A. F. BARDAMID \\ Kiev National University \\ Kiev, Ukraine
}

A. I. BELYAYEVA, A. A. GALUZA

Kharkov Technical University

61002 Kharkov,Ukraine

\section{Introduction}

Beryllium has a number of unique properties in comparison to all other metals. Due to the fact that it has the highest stiffness to density ratio of all structural metals, beryllium is widely used in components of space satellites, mirrors in particular. As a mirror material, beryllium has a definite advantage over many other metals, namely, its reflectance in the nearest UV (in the wavelength range 0.1-0.25 $\mu \mathrm{m}$ ) can reach $\sim 60 \%$, i.e., is higher than in the visible range [1]. Because of its lowest atomic number of structural metals, beryllium has been used for about ten years for the protection of vacuum vessel walls in the largest fusion device under operation (JET) [2] and was chosen as a protection material for the experimental fusion reactor (ITER) [3]. In connection with these applications, a great number of experiments have been under way for a long time. These relate different effects of interaction of beryllium with hydrogen isotopes in different energy and flux ranges. However, there have been no publications devoted to the effects of hydrogen isotope ion bombardment on the modification of optical properties of a beryllium mirror. In this paper we describe and analyze results obtained when beryllium mirrors were bombarded over a long period of time by ions of deuterium plasma in the keV energy range. 


\section{Optical Properties of Beryllium and BeO}

The majority of experimental data on the published optical properties of $\mathrm{Be}$ were reviewed by Arakawa et. al. [1]. Their data demonstrate that the reflectance, $\mathrm{R}$, of $\mathrm{Be}$ is practically independent of wavelength in the range $\lambda=300-700 \mathrm{~nm}$ and significantly increases for shorter wavelengths, reaching a maximum at $\sim 200 \mathrm{~nm}$. The reflectance strongly depends on the technology of mirror preparation and was highest for a Be film deposited in a high vacuum: up to $\mathrm{R} \approx 55 \%$ in the visible range. As for the different bulk processed beryllium mirrors the reflectance was at the level $\mathrm{R} \sim 45 \%$ [1] in the same range of wavelength. The approximate constancy of $\mathrm{R}$ in the indicated wavelength range is an attractive peculiarity of a Be mirror, compared to mirrors of some other materials, such as $\mathrm{Cu}$ for example [4].

It has been shown by other work $[5,6]$ that a beryllium oxide film is very transparent, having an extinction index equal to zero in the wavelength range of interest. The index of refraction of $\mathrm{BeO}$ is near 1.7 and is also practically independent of wavelength.

\section{Features of Behavior of BeO Under Bombardment by D Ions}

As has been shown by Sharapov and co-workers (e.g. [7,8]), under D ion bombardment the $\mathrm{BeO}$ film on the Be surface is transformed into a $\mathrm{Be}(\mathrm{OD})_{2}$ film by the process:

$$
2 \mathrm{BeO}+2 \mathrm{D} \rightarrow \mathrm{Be}(\mathrm{OD})_{2}+\mathrm{Be}+0.7 \mathrm{eV} / \mathrm{D} .
$$

It is seen from this reaction that one free Be atom is liberated per every molecule of hydroxide production. This atom, in the case of an imperfect high vacuum, can again react with a residual oxygen atom. Thus, in spite of continuing bombardment of the $\mathrm{Be}$ specimen by deuterium ions, the oxygen-containing film can grow with time on its surface. In practice, the increase in thickness of an oxygen-containing film on a $\mathrm{Be}$ surface bombarded by $\mathrm{D}$ ions has been observed in other experiments $[9,10]$.

The hydroxide film is not absolutely stable and disintegrates to oxide and water. Sharapov, et. al. [8] estimated that at room temperature the characteristic time for hydroxide film disintegration is (1-3) $10^{4} \mathrm{~min}$. With an increase of exposure temperature this time should decrease [11].

\section{Experimental}

A CW electron cyclotron resonance discharge at frequency of $2.37 \mathrm{GHz}$ sustained in a conventional mirror type magnetic field was used as a plasma source. The stainless steel vacuum vessel was evacuated by a turbomolecular pump down to a pressure of $\sim 2 \times 10^{-4}$ $\mathrm{Pa}$. During sample exposure the deuterium was continuously fed into the vessel at a pressure of (3-5) $10^{-2} \mathrm{~Pa}$. Typical plasma parameters at injected UHF power of 200-400 W were as follows: $\mathrm{n}_{\mathrm{e}} \leq 10^{10} \mathrm{~cm}^{-3}$ and $\mathrm{T}_{\mathrm{e}} \sim 5 \mathrm{eV}$. The polished mirror sample (a round 
shape with diameter of $22 \mathrm{~mm}$ and $2.5 \mathrm{~mm}$ thick, or a rectangular shape of $13 \times 13 \times 4$ $\mathrm{mm}$ ) was inserted by a special holder into the plasma stream flowing out of the magnetic mirror. The holder can be negatively biased to voltage up to $1.5 \mathrm{kV}$. The ion current density to the sample was $\sim 1 \mathrm{~mA} / \mathrm{cm}^{2}$ and the average temperature was maintained near RT. The initial reflectance of samples in the wavelength range of $250-650 \mathrm{~nm}$ measured at normal incidence was rather close to the values for some bulk Be mirrors given in [1]. The Be mirrors were bombarded by ions of deuterium plasma in many serial steps with the time duration of each step from 2 to 80 minutes. After every step the spectral dependence of reflectance in the indicated wavelength range and the mass loss (with sensitivity $\sim 10 \mu \mathrm{g}$ ) were measured ex situ. Thus the dependence of reflectance on the total time duration of sample bombardment with ions of deuterium plasma, $R(t)$, was obtained.

At some "critical" points of the $\mathrm{R}(\mathrm{t})$ dependence (see below) the measurements of optical constants of the oxide-containing film on Be mirror surface, i.e., the film refraction and extinction indices, were obtained using a serial null ellipsometer at a wavelength $\lambda=632.8 \mathrm{~nm}$. In this method the phase shift of the electromagnetic wave reflected from the sample $(\Delta)$ and the azimuth of the restored linear polarization $(\Psi)$ are measured directly. Then by means of a computer program the optical parameters of the samples were calculated in the framework of a fictive model. This treated a homogeneous film on an isotropic absorbing substrate of the presumed surface quality, fitted to the experimental data by means of a least-squares regression analysis.

With the aim of checking the role of the process described in (1), the Be samples were annealed in vacuum at $300^{\circ} \mathrm{C}$ for a period of one hour after $\mathrm{D}$ ion bombardment.

\section{Results}

Figure 1 shows the evolution of the reflectance of a Be mirror (sample \#1) as a function of exposure time to ions of deuterium plasma of $1.35 \mathrm{keV}$ energy. As seen, after a quite short time of exposure (20 minutes), the reflectance of the beryllium mirror drops by 5-8 $\%$, depending on the wavelength of reflecting light. The details of the sharp drop were cleared up by shortening the time of initial exposure in identical tests with other $\mathrm{Be}$ samples. It was found that a similar sharp drop of reflectance starts to become apparent (for $1.35 \mathrm{keV}$ accelerating voltage) after only 3-5 minute exposure time. Such a phenomenon has never been observed in similar tests for mirrors of other metals $(\mathrm{Cu}$, $\mathrm{SS}, \mathrm{Mo}, \mathrm{W}, \mathrm{Ta}$ ). It is important to note that after such short exposures, no measurable decrease of the mass of Be samples was observed, and this means that the development of surface roughness due to sputtering erosion can be neglected as the reason for the reflectance deterioration. Much longer exposure duration has to be used to obtain mass loss values that can be measured with confidence, and at this stage of the test (i.e., starting from the second exposure for the results shown in Figure 1) an approximate proportionality of the mass loss to the total exposure time was observed. So, the much slower rate of reflectance degradation observed after the sharp drop can be attributed to the modification of the microrelief of the mirror surface (increasing roughness). 
The last points in Figure 1, demonstrating the sharp rise of reflectance, were obtained as result of annealing of the sample after the last exposure to ion flux (total exposure time $\mathrm{t}=380 \mathrm{~min}$ ) and are shown with a shift along the $\mathrm{X}$-axis only for better visual perception.

The ellipsometry measurements for this sample were carried out for the following points along the X-axis: before any exposure to ion bombardment $(\mathrm{t}=0)$, immediately after the sharp drop of reflectance $(\mathrm{t}=20 \mathrm{~min})$, and after annealing the sample (these values of reflectance are shown at the position marked $\mathrm{t}=400 \mathrm{~min}$ ). The corresponding ellipsometrical parameters $(\Delta$ and $\Psi$ ) as functions of the incident light are presented in Figure 2 for these stages of the test.

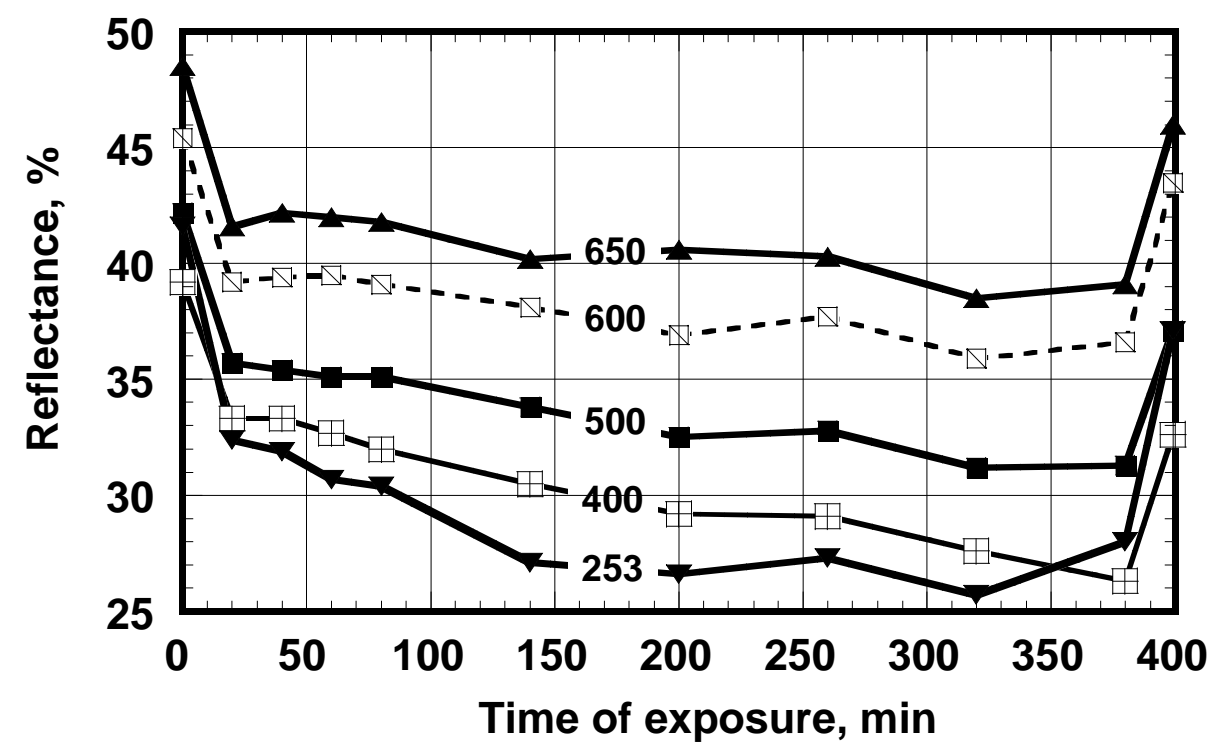

Figure 1. Dependences of the reflectance of a beryllium mirror at indicated wavelengths on the time of bombardment with ions of deuterium plasma $\left(\mathrm{E}_{\mathrm{i}}=1.35 \mathrm{keV}\right)$ for indicated wavelengths, followed by an annealing procedure (shown by the rise at the end of each plot). 

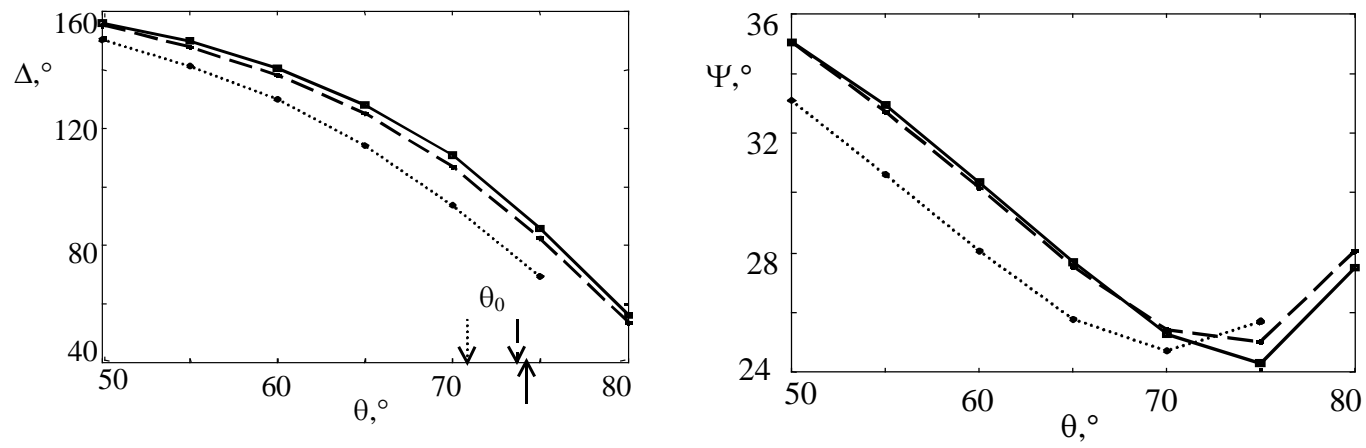

Figure 2. Dependences of the ellipsometric parameters $\Delta$ and $\Psi$ on the angle of incident light for a Be mirror: before exposure (solid line); after a quite short time of exposure to ions of stationary deuterium plasma $(\mathrm{t}=20$ min, $\mathrm{E}_{\mathrm{i}}=1.35 \mathrm{keV}$ ) (dotted line) and after annealing (dashed line).

The data of Figure 2 show the appreciable shift of the dependences of both ellipsometric parameters $\Delta$ and $\Psi$ on the angle of incident light after a short time of exposure to ions of stationary deuterium plasma (when the sputtering erosion can be neglected, as mentioned above). A significant decrease of the principal angle $\Theta_{0}$ was observed at the same time as the normal incidence beryllium reflectance $\mathrm{R}_{\exp }(\lambda=632.8 \mathrm{~nm}$.) shows $\sim 8 \%$ drop, in agreement with measurements of the spectral reflectance (Figure 1). The curves of Figure 2 did nearly return back to the first positions after annealing of the Be sample at $300^{\circ} \mathrm{C}$ for a period of 1-3 hours (the solid lines almost coincide with the dashed ones). So both methods, i.e., the measurements of the reflectance over a wide wavelength range (Figure 1) and the ellipsometry data for the red line (Figure 2) demonstrates the reversible behavior of the optical properties of an oxide-containing film on a Be mirror surface.

From the ellipsometric parameters, the refraction and extinction indices for an oxygencontaining film before and after bombardment of the Be mirror by ions of deuterium plasma were obtained using the model shown in Figure 3.

Air $\left(\mathrm{n}_{\mathrm{a}}=1\right)$

Film $\mathrm{BeO}$

$\left(\mathrm{n}_{\mathrm{f}}=1.725, \mathrm{k}_{\mathrm{f}}=0, \mathrm{~d}_{\mathrm{f}}=5 \mathrm{~nm}\right)$

Substrate Be

$\left(\mathrm{n}_{\mathrm{S}}=2.75, \mathrm{k}_{\mathrm{S}}=2.54\right)$
$\operatorname{Air}\left(\mathrm{n}_{\mathrm{a}}=1\right)$

Film Be(OD) $)_{2}$

$\left(\mathrm{n}_{\mathrm{f}}=2.76, \mathrm{k}_{\mathrm{f}}=0.11, \mathrm{~d}_{\mathrm{f}}=10 \mathrm{~nm}\right)$

Substrate

$\left(\mathrm{n}_{\mathrm{S}}=2.75, \mathrm{k}_{\mathrm{S}}=2.54\right)$

Figure 3. Model of the sample: a) Be nonexposed and b) Be exposed. 


\section{Discussion}

We propose that the initial sharp drop of $\mathrm{R}(\mathrm{t})$ dependence is brought about by the transformation of the $\mathrm{BeO}$ film into a $\mathrm{Be}(\mathrm{OD})_{2}$ film due to the bombardment of the $\mathrm{Be}$ mirror by deuterium ions in accordance with the process described by equation (1). The basis for such a conclusion is the fact that the sharp drop of $\mathrm{R}$ takes place without any change of the mass of sample, i.e., much earlier than any modification of the surface morphology could be realized. This possibility is supported by the final increase of reflectance after annealing (in Table 1 the initial decrement values of reflectance are very close to the final increments of $\mathrm{R}$ just after annealing), and by the approximate restoration of ellipsometric parameters after sample annealing. It follows from the ellipsometry data that the extinction index of a beryllium hydroxide film is not negligible compared to a $\mathrm{BeO}$ film $[5,6]$.

Table 1. The relation for different wavelengths between the decrement of initial sharp drop and the increment of a sharp rise (after annealing) of reflectance of sample \#1.

\begin{tabular}{|l|l|l|l|l|l|l|}
\hline Wavelength & $650 \mathrm{~nm}$ & $600 \mathrm{~nm}$ & $500 \mathrm{~nm}$ & $450 \mathrm{~nm}$ & $300 \mathrm{~nm}$ & $253 \mathrm{~nm}$ \\
\hline Decrement, \% & 6.9 & 6.2 & 6.5 & 5.9 & 5.4 & 9.2 \\
\hline Increment, \% & 6.9 & 6.9 & 5.8 & 6.3 & 6.3 & 9.1 \\
\hline
\end{tabular}

The nearly full restoration of the initial optical properties found by both the $R(\lambda)$ and ellipsometrical measurements, as a result of annealing the mirror after it has been bombarded by deuterium ions, is probably a result of the decomposition of $\mathrm{Be}(\mathrm{OD})_{2}$ film according to the following process [8]:

$$
\mathrm{Be}(\mathrm{OD})_{2} \rightarrow \mathrm{BeO}+\mathrm{D}_{2} \mathrm{O}
$$

In Table 2 we compare the reflectivity values directly measured $\left(\mathrm{R}_{\text {exp }}\right)$ and calculated from ellipsometrical parameters, $\left(\mathrm{R}_{\mathrm{c}}\right)$ before and after short time of ion bombardment and after annealing. For calculation of $R_{c}$, the model values of $n_{s, f}$ and $k_{s, f}$ and $d_{f}(F i g .3$ a,b) were used in formula taken from [12]. The indices for the clean beryllium surface, $\mathrm{n}=2.75$ and $\mathrm{k}=2.54$, and for the Be oxide film, $\mathrm{n}=1.725$ and $\mathrm{k}=0$, obtained in the framework of our simulation coincide quite well with values given in [1] for bulk beryllium mirrors and in [6] for $\mathrm{BeO}$ film. This good agreement means that our model simulation is approximately correct.

Table 2. The experimental $\left(\mathrm{R}_{\text {exp }}\right)$ and calculated $\left(\mathrm{R}_{\mathrm{c}}\right)$ values for the normal incidence beryllium reflectance before and after ion bombardment, and after annealing.

\begin{tabular}{|l|l|l|}
\hline Sample & $\mathrm{R}_{\exp } \%$ & $\mathrm{R}_{\mathrm{c}} \%$ \\
\hline Be unirradiated & 46.9 & 45 \\
\hline Be irradiated & 39.1 & 35,1 \\
\hline Be after annealing & 45 & 45 \\
\hline
\end{tabular}


In Table 3, data are presented for an experiment with another Be mirror which was subjected to ion flux for short-time exposures only (a few minutes) and then was annealed without long-time exposures which could have resulted in sputtering of the surface. However, it follows from Table 3 that after annealing, for this particular sample the more-or-less full restoration of reflectance to the initial level takes place for the longest wavelength of the investigated range only $(\lambda=650 \mathrm{~nm})$, and the difference between initial and restored $\mathrm{R}$ values increases with decreasing wavelength. We do not know the reason for this difference between the two samples. It could probably be connected with the history of sample fabrication and we hope to understand this difference by means of additional experiments.

Table 3. Reflectance of a Be mirror after short-term bombardments and following annealing (Be sample \#2).

\begin{tabular}{|l|l|l|l|l|l|l|}
\hline & $\begin{array}{l}\mathrm{R}, \%, \\
650 \mathrm{~nm}\end{array}$ & $\begin{array}{l}\mathrm{R}, \\
600 \mathrm{~nm}\end{array}$ & $\begin{array}{l}\mathrm{R}, \\
500 \mathrm{~nm}\end{array}$ & $\begin{array}{l}\mathrm{R}, \quad \%, \\
400 \mathrm{~nm}\end{array}$ & $\begin{array}{l}\mathrm{R}, \quad \%, \\
350 \mathrm{~nm}\end{array}$ & $\begin{array}{l}\mathrm{R}, \%, \\
253 \mathrm{~nm}\end{array}$ \\
\hline Initial & 47 & 45.6 & 44 & 41 & 40.5 & 45.7 \\
\hline 3 min & 36 & 34.2 & 30.7 & 27.3 & 27.4 & 22.4 \\
\hline $3+5$ min & 35.5 & 33.3 & 29.6 & 26.5 & 24.7 & 18.5 \\
\hline 3+5+5 min & 37.3 & 35.3 & 32.7 & 31 & 30 & 25.7 \\
\hline Annealing 1 & 44.2 & 43.5 & 41.1 & 39.3 & 36.5 & 35.2 \\
\hline Annealing 2 & 46.3 & 43.2 & 41.8 & 38.9 & 38.1 & 33.2 \\
\hline 5 min & 35.7 & 34.1 & 30.5 & 27.8 & 26.7 & 19.8 \\
\hline
\end{tabular}

Annealing 1: 300C-1 hour, 350C-1 hour;Annealing 2: 350C-4 hours.

\section{Conclusions}

It has been shown that optical methods are quite powerful tools for investigating the interaction of beryllium with hydrogen isotopes. The good sensitivity of these methods was demonstrated, and in addition, they can be applied for in situ measurements.

It was found that the transformation of oxide film into a hydroxide film plays an important role in the behavior of beryllium mirrors subjected to bombardment by deuterium ions. The significant drop of reflectance connected with such a transformation occurs for Be mirrors exposed to an air atmosphere, then exposed to an ion fluence exceeding $2 \cdot 10^{17}$ ions $/ \mathrm{cm}^{2}$. To avoid a similar degradation of optical properties for $\mathrm{Be}$ mirrors in service, they should be maintained at an elevated temperature.

\section{Acknowledgements}

The authors are grateful for the support of the Civilian Research and Development Foundation which is funding work at the Kharkov Institute of Physics and Technology. Partial support by the U.S. Department of Energy is also much appreciated. 


\section{References}

[1] E.T.Arakawa, T.A.Callcott and Yun-Ching Chang. Beryllium. In the Handbook of Optical Constants of Solids II, edited by E.D.Palik, Academic Press, 1991, p.42.

[2] The JET Team, presented by P.R.Thomas. Results of JET operation with beryllium. - J. Nucl. Mater. 176 \& 177 (1990) 3

[3] V.Barabash, S.Tanaka, R.Matera and the ITER JCT. Beryllium assessment and recommendation for application in ITER plasma facing components. Proc. $3^{\text {rd }}$ IEA Intern. Workshop on Beryl. Techn. for Fusion, Oct. 1997, Mito, Japan, p.2.

[4] Handbook of Optical Constants of Solids, vols. I and II, E.D.Palik Editor, Academic Press, 1985 and 1991.

[5] Von H. Gruner. Einige lichtoptische Eigenschaften rektiv aufgedampfter Berylliumoxid-Schichten. Optik, Heft 4 (1974) 443.

[6] D.F.Edwards, R.H.White. Beryllium oxide (BeO). Ibid [4], vol. II, p.805.

[7] V.M.Sharapov, L.E.Gavrilov, V.S.Kulikauskas, A.V.Markin. Deuterium accumulation in beryllium in contact with atomic deuterium at 740 K. - J. Nucl. Mater. 233-237 (1996) 870.

[8] V.M.Sharapov, V.Kh.Alimov, L.E.Gavrilov. Deuterium accumulation in beryllium oxide layer exposed to deuterium atoms. - J. Nucl. Mater. 258-263 (1998) 803.

[9] R.A.Langley. Interaction of implanted deuterium and helium with beryllium: Radiation induced oxidation. - ibid. 85-86 (1979) 1123.

[10] V.N.Chernikov, V.Kh.Alimov, A.V.Markin et al. Gas swelling and related phenomena in beryllium implanted with deuterium ions. --ibid. 228 (1996) 47.

[11] P. J. Spencer, O. von Goldbeck, R. Ferro, K. Girgis and A.L. Dragoo, "Beryllium: Physico-Chemical Properties of its Compounds and Alloys," Atomic Energy Review, Special Issue \#4, O. Kubaschewski, Editor, International Atomic Energy Agency, Vienna (1973) p. 23

[12] G. Hass. Influence of purity, substrate temperature and aging conditions on the reflectance of evaporated aluminium. - JOSA, 47 (1975), 1070. 